\title{
НАРУШЕНИЯ ФУНКЦИИ ЖЕЛУДОЧНО-КИШЕЧНОГО ТРАКТА ПРИ COVID-19 У ДЕТЕЙ
}

Попова Р.А. ${ }^{1,2}$, Руженцова Т.А. ${ }^{1}$, Хавкина Д.А. ${ }^{1}$, Чухляев П.В. ${ }^{1}$, Гарбузов А.А. ${ }^{1}$, Мешкова Н.А. ${ }^{3}$

1 - ФБУН ЦНИИ Эпидемиологии Роспотребнадзора г. Москва,

2 - ГБУЗ МО ГБУЗ МО «МГКБ», г. Мытищи,

3 - ФГАОУ ВО Первый МГМУ имени И.М. Сеченова Минздрава России

(Сеченовский Университет)

Резюме

Цель исследования - изучить особенности нарушений функции желудочнокишечного тракта у детей, больных коронавирусной инфекцией, вызванной вирусом SARSCoV-2.

\section{Материалы и методы}

Проанализированы данные историй болезней 36 детей, находившихся на лечении с диагнозом: внебольничная пневмония коронавирусной этиологии (вирус SARS-CoV-2 идентифицирован) в детском инфекционном отделении ГБУЗ МО «МГКБ» г. Мытищи. Большинство пациентов имели средне-тяжелую форму заболевания (96\%), тяжелых форм не было. Возраст детей был от 8 месяцев до 17 лет. Всем детям в 1-й день госпитализации был проведен клинический осмотр, рентгенографии или компьютерной томографии (KT) легких, анализы крови клинический и биохимический, коагулограмма, общий анализ мочи. Пациенты получали терапию в условиях стационара в течение 8-15 дней стационарного лечения. За этот период оценка клинического статуса проводилась не реже 1 раза в день, дополнительное обследование - не реже 1 раза в 7 дней, по показаниям - чаще. Вирус SARSCoV-2 был идентифицирован методом полимеразной цепной реакции (ПЦР). Все пациенты получали стандартную терапию в соответствии с временными методическими рекомендациями, по показаниям - другие лекарственные средства.

Результаты и обсуждение

Желудочно-кишечные нарушения проявлялись у пациентов на 4-5 день у 23х детей (64\%) и продолжалась от 3 до 5 дней. У большинства детей отмечали диарею (64\%) и боли в животе (57\%). Другие симптомы, свидетельствующие о дисфункции желудочно-кишечного тракта, были зарегистрированы у 67\% детей.

Выводы

Желудочно-кишечные нарушения имеются у большинства детей, госпитализированных с внебольничной пневмонией, вызванной вирусом SARS-CoV-2. 
Симптоматика купируется при проведении курса основной терапии, показанной для лечения COVID-19, и дополнительной, рекомендуемой при острых кишечных инфекциях.

Ключевые слова: абдоминальная боль, дети, диарея, коронавирус, пневмония, COVID-19, SARS-CoV-2.

\section{Введение}

Нарушения функции желудочно-кишечного тракта (ЖКТ) нередко сопровождают острые респираторные вирусные инфекции (ОРВИ). Наиболее часто сочетание симптоматики регистрируются при ротавирусной инфекции, реже - при норавирусной, аденовирусной инфекции, бока- и метапневмовирусной инфекции, гриппе. Механизм вовлечения в инфекционно-воспалительный процесс может быть различным. Возможно как непосредственное действие возбудителя на те, или другие клетки ЖКТ с их прямым поражением и последующим апоптозом, так и косвенное, посредством нарушений кровотока или нервной регуляции. Вирус SARS-CoV-2 взаимодействует преимущественно с рецепторами ангиотензин-превращающего фермента 2 типа (АПФ-2), которые присутствуют в разных тканях, в том числе на клетках эпителия ЖКТ и на эндотелии кровеносных сосудов [1-3]. Почти с самого начала изучения новой коронавирусной инфекции стало понятно, что, наряду с симптомами поражения дыхательных путей и интоксикацией, у пациентов нередко отмечаются желудочно-кишечные нарушения. В некоторых случаях сложно определить, связана ли симптоматика с инфекционным агентом или же с проводимой терапией. Однако, вне зависимости от причины, диарея и рвота могут приводить к обезвоживанию с развитием гиповолемического шока, электролитному дисбалансу и метаболическим нарушениям.

Цель исследования - изучить особенности нарушений функции желудочнокишечного тракта у детей, больных коронавирусной инфекцией, вызванной вирусом SARSCoV-2.

\section{Материалы и методы}

Проанализированы данные историй болезней 36 детей, находившихся на лечении с диагнозом: внебольничная пневмония коронавирусной этиологии (вирус SARS-CoV-2 идентифицирован) в детском инфекционном отделении ГБУЗ МО «МГКБ» г. Мытищи с марта по июль 2020 года. Большинство пациентов имели средне-тяжелую форму заболевания (96\%), тяжелых форм не было. Возраст детей был от 8 месяцев до 17 лет. Большинство пациентов были в возрасте от 8 месяцев до 3 лет (36\%), 3 - 6 лет - 22\%, 6 - 10 лет - 14\%, 10 - 17 лет - 28\%. Длительность наблюдения на дому до момента госпитализации составляла от трех до восьми дней. Всем детям в 1-й день госпитализации были выполнены 
клинический осмотр, рентгенография или компьютерная томография (KT) легких, анализы крови клинический и биохимический, коагулограмма, общий анализ мочи, анализ мазка из зева и носа на вирус SARS-CoV-2 методом полимеразной цепной реакции (ПЦР). При наличии диареи проводили бактериологическое исследование кала для идентификации возбудителей кишечной группы (сальмонелл, шигелл, эшерихий, кампилобактера) и иммуноферментный анализ для исключения рота- или норавирусной инфекции. При выявлении каких-либо других возбудителей, помимо SARS-CoV-2, пациенты исключались из данного наблюдения.

В стационаре дети находились в течение 8 - 15 койко-дней до выздоровления или устойчивого улучшения с наличием не менее 2 отрицательных результатов анализа мазка из зева и носа на наличие вируса SARS-CoV-2. За этот период оценка клинического статуса проводилась не реже 1 раза в день, дополнительное обследование - не реже 1 раза в 7 дней, по показаниям - чаще.

Пациенты получали терапию в соответствии с временными методическими рекомендациями по ведению больных с COVD-19, при желудочно-кишечных нарушениях дополнительно, по показаниям, диета с исключением сырых фруктов и овощей, молочных продуктов и продуктов, стимулирующих газообразование, а также другие лекарственные средства. Всем детям была назначена антибактериальная терапия (цефалоспорины Цефтриаксон внутримышечно - в 98\%, макролиды - азитромицин перорально - в 2\%), пробиотики (Бифидумбактерин - в 89\%, Бак-сет - в 11\%,) и противовирусная терапия (Гриппферон назально - в 87\% или Кипферон - в 13\%). По диагнозу пневмония дети получали муколитики (в 97\%), антисептики (в 87\%), кортикостероиды (в 37\%), бронхолитики (в 64\%), антигистаминные препараты (в 24\%). При диарейном синдроме назначали стандартную оральную (50\%) или пероральную (15\%) регидратационную терапию, энтеросорбенты (диоктаэдрический смектит, Смекту или диоксид кремния коллоидный, Полисорб - 14\%). При гемоколите в схему лечения добавляли антигеморрагические средства (Викасол внутримышечно - в 13\%). При симптомах ферментативной недостаточности после купирования острой диареи назначали ферменты (Креон или Панкреатин - в 67\%). Парацетамол в качестве жаропонижающего средства дети получали при температуре более $38-39^{\circ} \mathrm{C}$, в соответствии с современными рекомендациями.

\section{Результаты и обсуждение}

У всех детей при поступлении отмечали симптомы интоксикации со снижением аппетита, слабостью, сонливостью, утомляемостью, редкий сухой кашель. Температура тела была выше нормы у 96\% пациентов, при этом максимальное значение составило $38.2^{\circ} \mathrm{C}$. 
При анализе анамнеза и клинической картины в динамике было установлено, что диарея отмечалась с четвертых-пятых суток заболевания у 23 детей (64\%) и продолжалась от трех до пяти дней. Стул был жидким, слизистым, в единичных случаях (в 13\% от общего числа детей) с прожилками крови. Частота стула у большинства детей была до 5 раз в сутки, максимально - до 8 раз.

Выраженность и продолжительность болей в животе оценивали только в группе детей старше 3 лет. Среди этих пациентов абдоминальный болевой синдром был выражен у 13 детей (57\%), в большинстве случаев по срокам появления и продолжительности соответствовал диарейному синдрому. Рвоты не было отмечено ни в одном случае.

Положительный ответ на терапию был достаточно быстрый, коррекции схемы в большинстве случаев не требовалось. После купирования диареи нередко сохранялись плохой аппетит, тошнота, дискомфорт после еды, метеоризм, что было поводом для назначения препаратов на основе ферментов. К моменту выписки из стационара у всех пациентов симптомы нарушений функции желудочно-кишечного тракта были купированы.

Таким образом, диарея и абдоминальные боли наблюдаются у большинства детей, госпитализированных с пневмонией, вызванной SARS-CoV-2. Купирование симптоматики на фоне продолжения противовирусной и антибактериальной терапии указывает на непосредственное участие коронавируса в патогенезе и может опровергать возможное влияние дисбиотических нарушений с активизацией роста условно-патогенной флоры, а также дисфункцию гепато-билиарной системы, что нельзя исключить при применении, в первую очередь, цефалоспоринов. Высокая частота регистрации желудочно-кишечных нарушений, у многих детей до начала терапии, подтверждает тропность нового коронавируса к ЖКТ. Большое число случаев дискомфорта в животе поле еды, тошноты, метеоризма, свидетельствует о, вероятно, развивающейся при коронавирусной ферментопатии и возможном вовлечении в инфекционно-воспалительный процесс поджелудочной железы и гепато-билиарной системы, что требует дальнейшего изучения.

\section{Выводы}

Желудочно-кишечные нарушения имеются у большинства детей, госпитализированных с внебольничной пневмонией, вызванной вирусом SARS-CoV-2. Диарея выявлена в 64\%, абдоминальный болевой синдром - у 57\%, другие симптомы, свидетельствующие о дисфункции желудочно-кишечного тракта, - в 67\%. Симптоматика купируется при проведении курса основной терапии, показанной для лечения COVID-19, и дополнительной, рекомендуемой при острых кишечных инфекциях. 


\section{Сведения об авторах}

Попова Раиса Викторовна - лаборант - исследователь клинического отдела инфекционной патологии Федерального бюджетного учреждения науки «Центральный научно-исследовательский институт эпидемиологии» Федеральной службы по надзору в сфере защиты прав потребителей и благополучия человека; 111123, г. Москва, ул. Новогиреевская, д. ЗА; тел. +7-495-672-11-58; врач ГБУЗ МО ГБУЗ МО «МГКБ», г. Мытищи; e-mail: raiakotova@gmail.com ORCID: 0000-0003-3324-3554 .

Руженцова Татьяна Александровна - доктор медицинских наук, руководитель отдела клинических исследований, профессор образовательного центра Федерального бюджетного учреждения науки «Центральный научно-исследовательский институт эпидемиологии» Федеральной службы по надзору в сфере защиты прав потребителей и благополучия человека; 111123, г. Москва, ул. Новогиреевская, д. ЗА; тел. +7-495-304-56-96; e-mail: ruzhencova@gmail.com; ORCID: 0000-0002-6945-2019.

Хавкина Дарья Александровна - статистик отдела клинических исследований Федерального бюджетного учреждения науки «Центральный научно-исследовательский институт эпидемиологии» Федеральной службы по надзору в сфере защиты прав потребителей и благополучия человека; 111123, г. Москва, ул. Новогиреевская, д. ЗА; тел. +7-495-304-56-96; e-mail: havkina@gmail.com; ORCID: 0000-0001-5919-9841.

Чухляев Павел Владимирович - методист отдела клинических исследований Федерального бюджетного учреждения науки «Центральный научно-исследовательский институт эпидемиологии» Федеральной службы по надзору в сфере защиты прав потребителей и благополучия человека; 111123, г. Москва, ул. Новогиреевская, д. ЗА; тел. +7-495-304-56-96; e-mail: pafachka@gmail.com, ORCID:0000-0003-1210-1215.

Гарбузов Александр Александрович - методист отдела клинических исследований Федерального бюджетного учреждения науки «Центральный научно-исследовательский институт эпидемиологии» Федеральной службы по надзору в сфере защиты прав потребителей и благополучия человека; 111123, г. Москва, ул. Новогиреевская, д. ЗА; тел. +7-495-304-56-96; e-mail: os.vertebra@gmail.com; ORCID: 0000-0002-3378-8418.

Мешкова Наталья Андреевна - студентка 3-го курса Клинического института детского здоровья им. Н.Ф. Филатова Федерального государственного автономного образовательного учреждения высшего образования «Первый Московский государственный медицинский университет имени И.М. Сеченова» Министерства здравоохранения Российской Федерации (Сеченовский университет); 119435, Москва, ул. Большая 
Пироговская, д. 2, стр. 4, тел. +7-903-520-07-46; e-mail: nataliaandreevnamesh@gmail.com; ORCID: 0000-0003-3904-7108.

\section{Конфликт интересов}

Авторы заявляют об отсутствии конфликта интересов

\section{Conflict of interests}

The authors claim that there is no conflict of interest.

\section{Список литературы}

1. Tang $\mathrm{X}, \mathrm{Wu} \mathrm{C}, \mathrm{Li} \mathrm{X}$, et al. On the origin and continuing evolution of SARS-CoV-2. National Science Review 2020.

2. World Health Organization. Director-General's remarks at the media briefing on 2019nCoV on 11 February 2020. https:/www.who.int/dg/speeches/detail/who-director-general-sremarks-at-the-media-briefing-on-2019-ncov-on-11-february-2020 (Accessed on February 12, 2020).

3. Хавкина Д.А., Руженцова Т.А., Чухляев П.В., Гарбузов А.А., Шушакова Е.К. Роль дезинтоксикационной и антиоксидантной терапии в лечении COVID-19: теория и практика. Эпидемиология и инфекционные болезни: актуальные вопросы. 2020: 62-69. DOI: https://dx.doi.org/10.18565/epidem.2020.2.62-69.

\section{References}

1. Tang $\mathrm{X}, \mathrm{Wu} \mathrm{C}, \mathrm{Li} \mathrm{X}$, et al. On the origin and continuing evolution of SARS-CoV-2. National Science Review 2020.

2. World Health Organization. Director-General's remarks at the media briefing on 2019nCoV on 11 February 2020. https://www.who.int/dg/speeches/detail/who-director-general-sremarks-at-the-media-briefing-on-2019-ncov-on-11-february-2020 (Accessed on February 12, 2020).

3. Khavkina D.A.., Ruzhencova T.A., Chukhliaev P.V., Garbuzov A.A., Shushakova E.K. The role of detoxication and antioxidation therapy COVID-19: theory and practicea. Epidemiology and infection diseases: actual questions. 2020: 62-69. DOI: https://dx.doi.org/10.18565/epidem.2020.2.62-69. 